\title{
AIAA 2001-4005 \\ Stability and Control Properties \\ of an Aeroelastic Fixed Wing \\ Micro Aerial Vehicle
}

Martin R. Waszak and Luther N. Jenkins

NASA Langley Research Center

Hampton, VA 23681-2199

Dr. Peter Ifju

University of Florida

Gainesville, Florida 32611-6250

\section{AIAA Atmospheric Flight Mechanics Conference 6-9 August 2001 Montreal, Canada}

For permission to copy or to republish, contact the copyright owner named on the first page. For AIAA-held copyright, write to AIAA Permissions Department, 1801 Alexander Bell Drive, Suite 500, Reston, VA, 20191-4344. 


\title{
STABILITY AND CONTROL PROPERTIES OF AN AEROELASTIC FIXED WING MICRO AERIAL VEHICLE
}

\author{
Martin R. Waszak ${ }^{*}$ and Luther N. Jenkins ${ }^{\dagger}$ \\ NASA Langley Research Center, Hampton, Virginia \\ Dr. Peter Ifju \\ University of Florida, Gainesville, Florida
}

\begin{abstract}
Micro aerial vehicles have been the subject of considerable interest and development over the last several years. The majority of current vehicle concepts rely on rigid fixed wings or rotors. An alternate design based on an aeroelastic membrane wing concept has also been developed that has exhibited desired characteristics in flight test demonstrations and competition. This paper presents results from a wind tunnel investigation that sought to quantify stability and control properties for a family of vehicles using the aeroelastic design. The results indicate that the membrane wing does exhibit potential benefits that could be exploited to enhance the design of future flight vehicles.
\end{abstract}

\section{Introduction}

Micro aerial vehicles, or "MAVs", are designated by the Defense Advanced Research Projects Agency (DARPA) as a class of aircraft with a maximum dimension of 6 inches and are capable of operating at speeds of $25 \mathrm{mph}$ or less. ${ }^{[1]}$ Developments in miniaturized digital electronics, communications, and computer technologies and strong support by DARPA have moved the prospect of very small autonomous flight vehicles from the realm of science fiction to science fact. The goal is for these vehicles to provide inexpensive and expendable platforms for surveillance and data collection in situations where larger vehicles are not practical. For example, they can be used for battlefield surveillance or mapping the extent of chemical/radiation spills or viral outbreaks. Equally useful civil applications include use in search and rescue operations, traffic/news coverage, and crop or wildlife monitoring. Many potential uses would require cooperative and collaborative control capabilities so that large numbers of MAVs could be used to cover a large operational area. In these types of applications

\footnotetext{
* Senior Research Engineer, Dynamics and Control Branch. Senior Member AIAA.

$\dagger$ Research Engineer, Flow Physics and Control Branch. ‡ Associate Professor, Department of Aerospace Engineering, Mechanics, and Engineering Science.
}

Copyright (C) 2001 by the American Institute of Aeronautics and Astronautics, Inc. No copyright is asserted in the United States under Title 17, U.S. Code. The U.S. Government has a royalty-free license to exercise all rights under the copyright claimed herein for Governmental purposes. All other rights are reserved by the copyright owner.

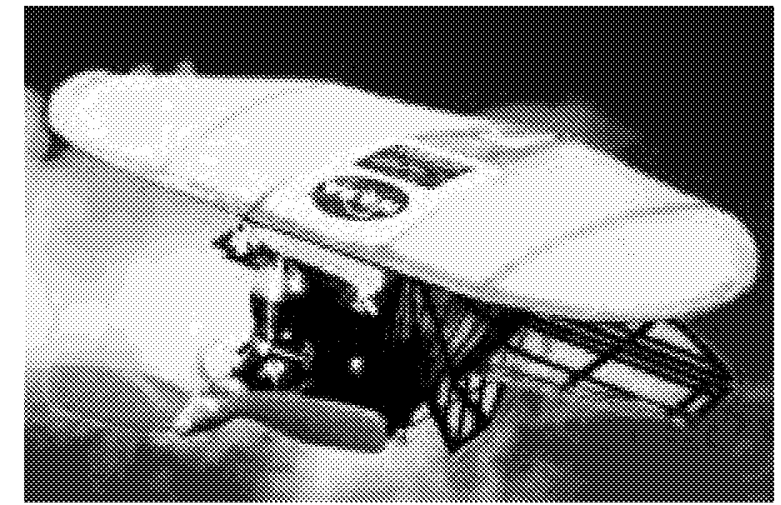

Figure 1 - photograph of Univ. of Florida MAV.

MAVs could be coordinated from a central base station or used in collaborative swarms to collect and transmit data.

The research and development required for developing MAVs and related systems is quite challenging and requires a number of technical advances that may benefit a broad range of aerospace applications. The development of a vehicle could also foster development of component technologies and may help to support an emerging growth market for micro aerial vehicles.

An aeroelastic fixed wing micro aerial vehicle concept has been developed by a team at the University of Florida with a goal to design a vehicle that could win the ISSMO (International Society of Structural and Multidisciplinary Optimization) Micro Aerial Vehicle Competition; a goal that was accomplished each of the last three years. ${ }^{[2,3]}$

The vehicle exploits an innovative aeroelastic wing with the ability to adapt to the atmospheric disturbances and provide smoother flight thus 
providing a better surveillance platform and making the vehicle easier to fly. This is accomplished via the passive mechanism of adaptive washout. This technique has been adapted from sailing vessels in which adaptive washout is produced through twist of the sail. This greatly extends the wind range of the sail and produces more constant thrust (lift), even in gusty wind conditions. Adaptive washout is produced in the MAV through extension of the membrane and twisting of the structure in response to changes in speed and vehicle attitude causing changes in angle of attack along the span. The effect is to reduce the response of the vehicle to disturbances.

The benefits of the flexible membrane wing appear substantial but have not yet been studied in detail. In addition, the nature of mirco aerial vehicles in general and the flexible wing concept in particular make analysis and design of the vehicle quite challenging. Despite this fact, the vehicle provides an excellent basis upon which to develop and apply ongoing research in dynamics and control, aeroservoelasticity, multi-functional structures, mircoelectronics, measurement and actuation systems, and many others.

NASA is collaborating with the University of Florida to develop an understanding of the underlying physical phenomena associated with the vehicle concept with a goal of enhancing the vehicle design and developing a capability for investigating autonomous and collaborative control technologies.

A wind tunnel test was performed to provide data with which to investigate the benefits of the aeroelastic wing concept and to support related research. This paper presents some of the key results of the wind tunnel test and analysis of these results in the context of stability and control. The data described here will also be the basis for a dynamic simulation model currently under development.

\section{Vehicle Description}

The University of Florida MAV (UFMAV) incorporates a high mounted wing and low mounted cruciform tail attached to a tapered fuselage with rectangular cross section (see figure 1). The fuselage is a truss-like design constructed of a graphite/epoxy material covered with a thin transparent monofilm membrane. A more detailed description of the vehicle and its construction can be found in reference 3 . Table 1 summarizes the pertinent geometric and mass properties of the vehicle.

A unique aspect of the vehicle is its flexible membrane wing. The cambered wing structure is constructed of unidirectional carbon fiber prepreg laminate forming a leading edge spar and chordwise ribs or battens. A membrane material is bonded to the
Table 1 - UFMAV geometric and mass properties.

\begin{tabular}{|l|l|}
\hline Empty Weight & $0.12 \mathrm{lbs}$ \\
\hline Wing Area & $19.8 \mathrm{in}^{2}$ \\
\hline Span & $6 \mathrm{in}$ \\
\hline Mean Chord & $3.3 \mathrm{in}$ \\
\hline Moments of Inertia: & \\
Ixx & $0.086{\mathrm{lb}-\text { in }^{2}}^{2}$ \\
Iyy & $0.23 \mathrm{lb}-$ in $^{2}$ \\
Izz & $0.21 \mathrm{lb}-$ in ${ }^{2}$ \\
Ixz & $0.037 \mathrm{lb}$-in \\
\hline
\end{tabular}

spar and batten. Several membrane materials with varying stiffness properties have been investigated and three of these will be described in this paper: a 4 mil thick flexible latex membrane, an inextensible monofilm membrane (the same material used in the fuselage construction), and a stiff graphite sheet.

The maximum dimension (including length and wing span) of the vehicle is six inches. The wing area is approximately 19.8 square inches. The root chord is 4.25 inches and the mean chord is 3.3 inches. The wing camber of the unloaded wing is approximately 6.5 percent of the root chord with the maximum camber occurring at approximately 30 percent chord and is uniform across the span. The wing is mounted at an incidence of approximately nine degrees where the wing incidence is defined as the angle between the root chord line and the longitudinal axis of the fuselage.

Control is accomplished using two independently controlled elevons that are actuated using small rotary servos. A small gas engine normally provides propulsion, but an electric motor was substituted during the wind tunnel test to better control propeller speed and reduce operational complexity. The propeller was three inches in diameter with a pitch of 1.25

\section{Wind Tunnel Test}

The wind tunnel test was conducted in the Basic Aerodynamics Research Tunnel (BART) at NASA Langley Research Center. ${ }^{[4,5]}$ The purpose of the test was to collect a variety of data to aid in the study of the dynamics and control properties of the UFMAV concept. The data consist of aerodynamic force and moment data measured with an external 6-component strain gauge balance, static wing deformation data from a projection moiré interferometry (PMI) system, ${ }^{[6]}$ dynamic wing deformation data from a high speed videogrammetry system, ${ }^{[7]}$ and digital video of flow visualization using smoke and helium bubbles. Figure 2 depicts the UFMAV mounted in the BART.

These data were collected for a rigid wing and three different batten/membrane arrangements over a range of 


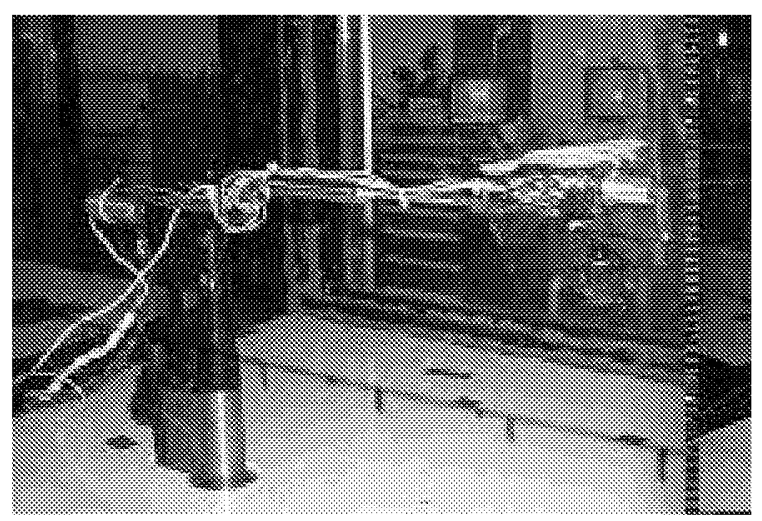

Figure 2 - UFMAV mounted in BART.

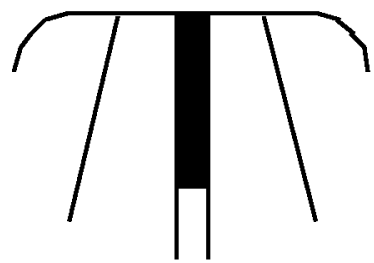

(a)

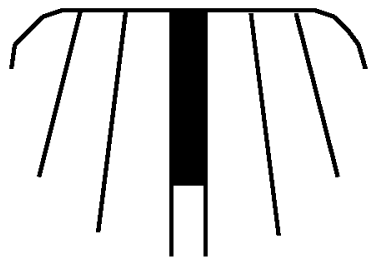

(b)

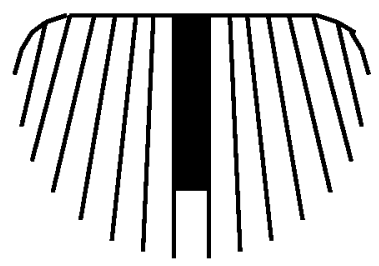

(c)

Figure 3 - batten arrangement for UFMAV wings:

(a) one-batten, (b) two-batten, (c) six-batten.

operating conditions determined by dynamic pressure, power setting, vehicle attitude, and control surface deflection. The different batten arrangements are depicted in figure 3. More flexibility and larger membrane stretch characterize the one-batten design. The two-batten design is, by comparison, stiffer and exhibits less membrane stretch under aerodynamic load. Both wings were tested using a 4 mil latex membrane. The six-batten wing was covered with an inextensible monofilm membrane that further increased the stiffness of the wing and exhibited less membrane deformation and vibration. The rigid wing was constructed of a two-batten frame covered with a graphite sheet.

Three dynamic pressure values were considered, $1.0 \mathrm{psf}, 1.6 \mathrm{psf}$, and $2.0 \mathrm{psf}$, and represent a range of speeds over which the actual vehicle operates. Two power settings were considered: power off (characterized by pinning the propeller) and the power associated with longitudinal trim (i.e. thrust offsets axial aerodynamic force, lift offsets weight, and zero pitching moment).

Vehicle attitude is represented by fuselage incidence angle (i.e., angle of attack) and sideslip angle. The angle of attack was varied between -5 and +42.5 degrees in 2.5 degree increments (though PMI data were only collected up to 30 degrees). The sideslip angle was varied between -5 and +5 degrees in 2.5 degree increments with the vehicle angle of attack fixed at zero degrees. Control inputs are characterized by symmetric and antisymmetric elevon deflections. Symmetric inputs were varied between -25 and +25 degrees in 5 degree increments. Antisymmetric inputs were varied between -20 and 20 degrees in 5 degree increments.

The static aerodynamic data were collected using a 6component strain gauge balance and resolved into lift, drag, side force, pitching moment, rolling moment, and yawing moment. Examples of the force and moment data collected during the test are presented in the Appendix (Figures A1 - A11).

Structural deformation data were obtained using two techniques: projection moiré interferometry $(\mathrm{PMI})^{[6]}$ and high-speed videogrammetry. ${ }^{[7]} \mathrm{PMI}$ was used to collect mean static deformation over a large fraction of the wing surface and the variance of the motions about the mean shape. Videogrammetry was used to collect dynamic deformation of selected points on the surface of the wing but only at a few selected operating conditions. The wing deformation data can be used to determine the manner and degree to which the wing (spar, battens, and membrane) deforms under aerodynamic loading.

Flow visualization was collected using digital video. Two methods were used: smoke flow and helium bubbles. The flow visualization data provide insight into the underlying flow phenomena and can be correlated with the aerodynamic and structural data.

\section{Analysis}

Additional wind tunnel data is needed before a complete quasi-static aerodynamic database will be available. The current data are sufficient to identify various aspects of the UFMAV's aerodynamic behavior. Some analysis results based on the available data are described below. The preliminary results characterize various aspects of aerodynamic performance, stability and control, and static aeroelastic behavior.

\section{Aerodynamic Performance}

Aerodynamic performance characterized by $\mathrm{L} / \mathrm{D}$ is summarized in figure 4 . These results represent $L / D$ of the UFMAV with the propeller restrained from rotation 


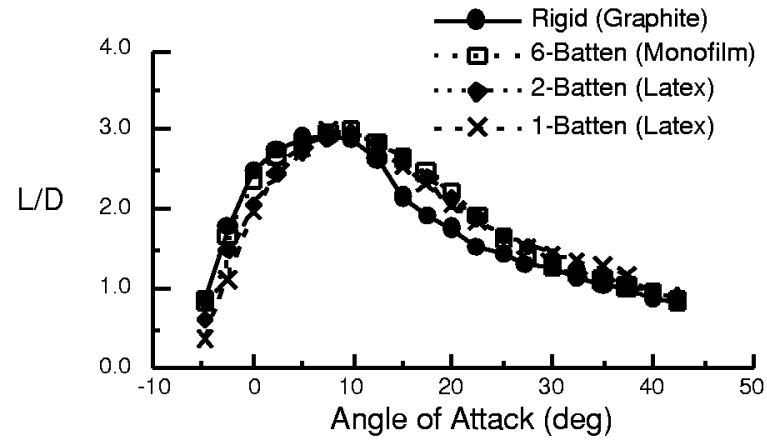

Figure 4 - L/D for various wing configurations, ( $q=1.6$ psf, prop pinned).

(i.e., pinned) for several wings with varying levels of stiffness. The maximum L/D of approximately 3.0 is relatively independent of wing configuration. However, maximum L/D occurs at incidences at approximately 7.5 degrees for the rigid wing and roughly 10 degrees for the other wing configurations. It is interesting to note that a comparable rigid fixed wing micro aerial vehicle, Aerovironment's Black Widow, has twice the maximum L/D of the vehicle described herein. ${ }^{[8]}$

An alternate fuselage configuration was assessed to determine the effect of streamlining on vehicle L/D. Figure 5 depicts the variation in L/D over a range of angles of attack for the baseline fuselage and a streamlined fuselage. Both fuselages had the same wing installed at the same incidence angle. The streamlined configuration had a 20 percent greater maximum L/D than the baseline configuration. There is a clear benefit to streamlining the fuselage that can be exploited in future designs.

Figure 6 depicts the lift curves for the various wing configurations. For small angles of attack all the wings demonstrate similar lift characteristics with the stiffer wings having slightly higher lift coefficient. However, it is clear that the membrane wings stall at much higher angles of attack than the rigid wing. In fact, the most flexible wing configuration has double the stall angle of the rigid wing configuration (35 degrees and 15 degrees, respectively, for the prop pinned case). This could be a key factor in enhancing the range of operation and agility of micro aerial vehicles.

While these results are similar to the results for other low aspect ratio, low Reynolds number wings presented in reference 9 there are important differences. At low angles of attack the aeroelastic wings behave like rigid wings with similar aspect ratio. The lift curve slope for the UFMAV is approximately 2.9 with the prop pinned. The lift curve slopes of similar rigid wings studied in Reference 9 at comparable Reynolds

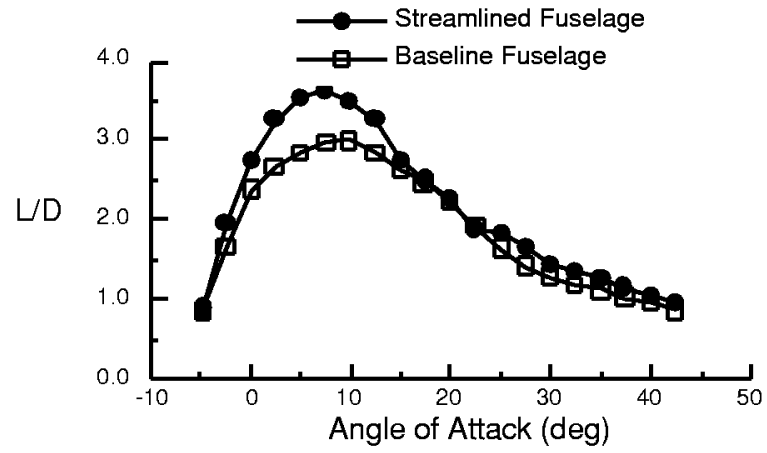

Figure 5-L/D versus angle of attack for streamlined and baseline fuselage configurations, ( $q=1.6$ psf, prop pinned, 6-batten wing).

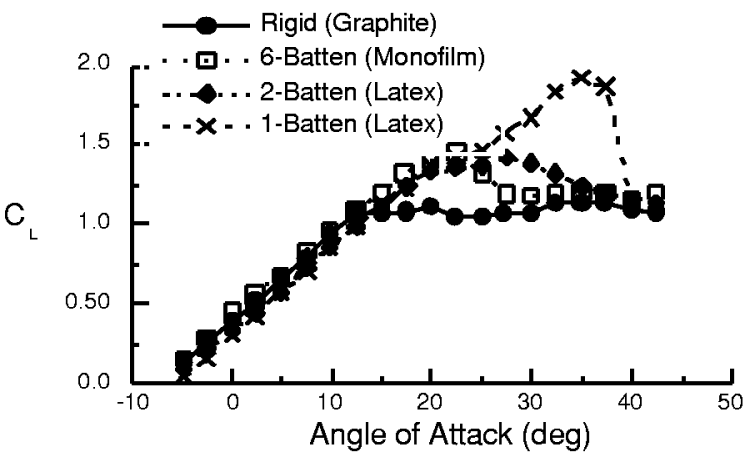

(a) $\mathrm{q}=1.6 \mathrm{psf}$, prop pinned

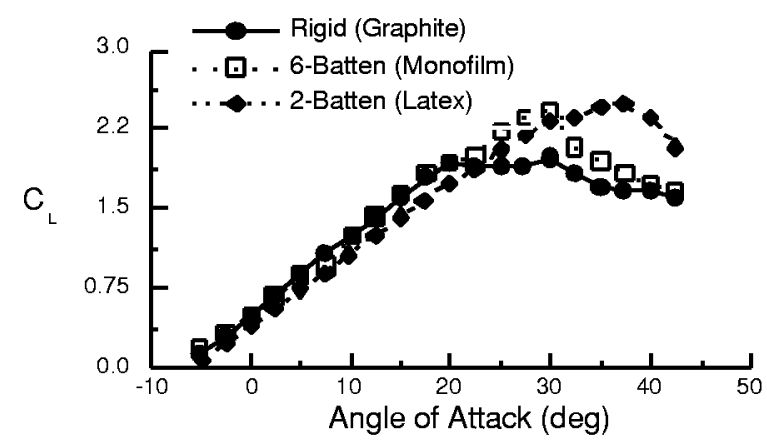

(b) $\mathrm{q}=1.6 \mathrm{psf}$, trim power

Figure 6- lift coefficient vs. angle of attack for configurations with varying wing stiffness.

number and aspect ratio $(\mathrm{Re}=70,000, \mathrm{AR}=2)$ are approximately 2.9 as well. However, these wings have stall angles between 12 and 15 degrees. The stall angles of the aeroelastic wings are between 30 and 45 degrees (i.e., stall angle of the vehicle plus the wing incidence angle) and are similar to that of much lower aspect ratio rigid wings ( $\mathrm{AR}=0.5$ to 1.0 ). However, the very low aspect wings exhibit lower lift curve slopes of 1.3 to 1.7 . The aeroelastic wings appear to exhibit the stall behavior similar to rigid aspect ratio 
0.5 to 1.0 wings and the lift generating capability of rigid aspect ratio 2.0 wings.

\section{Static Stability Properties}

The UFMAV exhibits static stability about the longitudinal and directional axes. Figure 7 depicts the pitching moment curve about the c.g. for the twobatten latex wing configuration (the other configurations are similar). The negative slope implies positive longitudinal static stability - a perturbation in angle of attack will produce a restoring pitching moment. The slope of this curve is approximately -0.6 per radian of incidence and is somewhat larger than typical piloted aircraft ${ }^{[10, p 19]}$ and corresponds to static margin of approximately 0.15 .

Figure 8 depicts the yawing moment curve for the two-batten latex wing configuration (the others are similar). Assuming the data can be approximated by a linear curve* the positive slope implies positive directional stability - a perturbation in sideslip will cause a restoring yawing moment. The slope of this curve is approximately 0.5 per radian of sideslip and somewhat larger than typical piloted aircraft. ${ }^{[10, p 112]}$

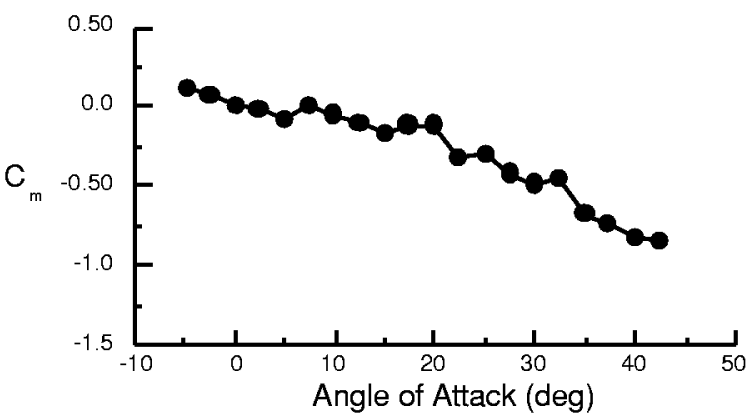

Figure 7 - pitching moment coefficient for two-battened latex configuration,

$(\mathrm{q}=1.5 \mathrm{psf}$, trim power)

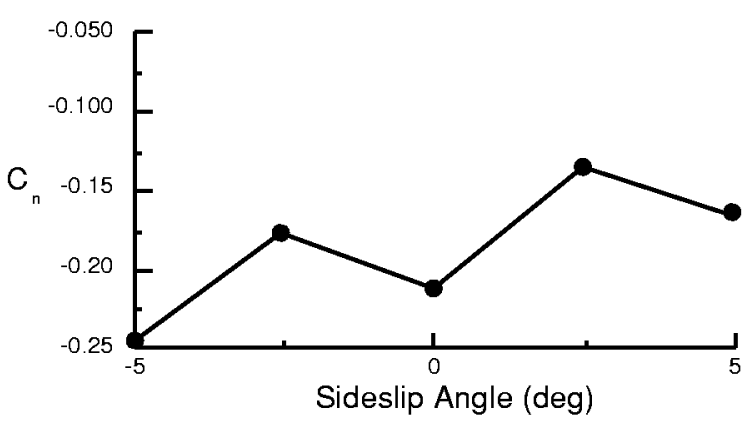

Figure 8 - yawing moment coefficient for two-battened latex configuration, $(\mathrm{q}=1.5 \mathrm{psf}$, trim power $)$.

\footnotetext{
* The error analysis presented in the Appendix and other data collected during the wind tunnel test suggest this is a reasonable assumption.
}

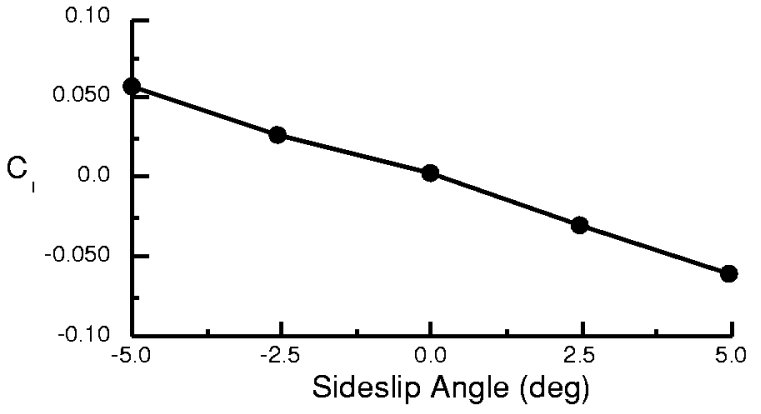

Figure 9 - rolling moment coefficient for two-battened latex configuration, $(\mathrm{q}=1.5 \mathrm{psf}$, trim power $)$.

The UFMAV also exhibits positive dihedral effect. This is evident in figure 9 where the rolling moment curve for the two-batten latex wing configuration is presented as a function of sideslip angle. The slope of -0.7 per radian of sideslip (considerably larger in magnitude than typical piloted aircraft ${ }^{[10, p 1[2]}$ ) indicates that a positive sideslip angle will induce a relatively large counterclockwise rolling moment.

\section{Control Properties}

The UFMAV exhibits both longitudinal and lateral/directional controllability. Figure 10 shows the lift and pitching moment coefficients as a function of symmetric elevon deflection at two different angles of attack -0 and 10 degrees. Symmetric elevon deflection affects both pitching moment and lift. The change in lift due to symmetric elevon is about 0.7 per radian and the change in pitching moment is about -0.4 per radian. These values are representative of a flying wing rather than a typical aircraft. The lift and moment curve slopes are not strongly dependent on angle of attack and, though not shown here, symmetric elevon has little effect on sideforce, rolling moment, and yawing moment.

Antisymmetric elevon deflection produces changes in side force, rolling moment and yawing moment. Figure 11 shows the side force, rolling moment, and yawing moment coefficients as a function of antisymmetric elevon deflection. Antisymmetric elevon has about the same magnitude of influence on side force and rolling moment. The change in side force and rolling moment due to antisymmetric elevon is approximately -0.10 per radian and 0.08 per radian, respectively. The change in yawing moment to antisymmetric elevon is about 0.06 per radian. Though not shown here, the effect of changes in angle of attack is small. The effect of changes in sideslip was not assessed. 


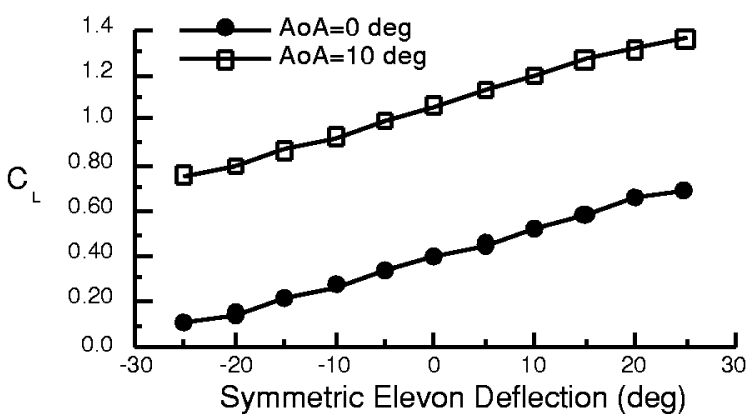

(a)

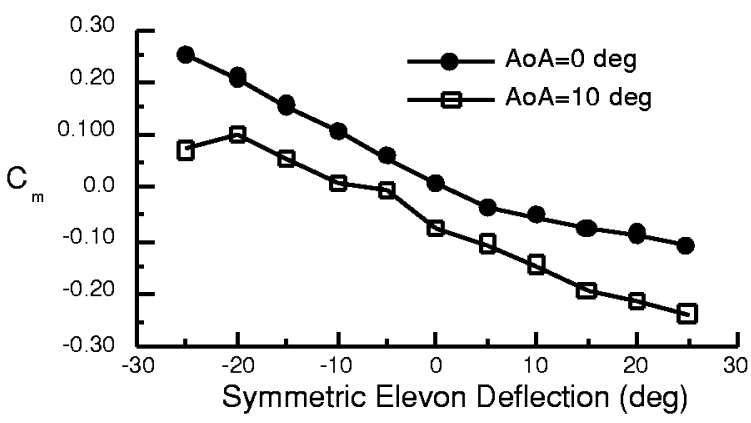

(b)

Figure 10 - lift and pitching moment coefficients due to symmetric elevon for two-batten latex config., $(q=1.6$ psf, trim power $)$ :

(a) lift coefficient, (b) pitching moment coefficient.

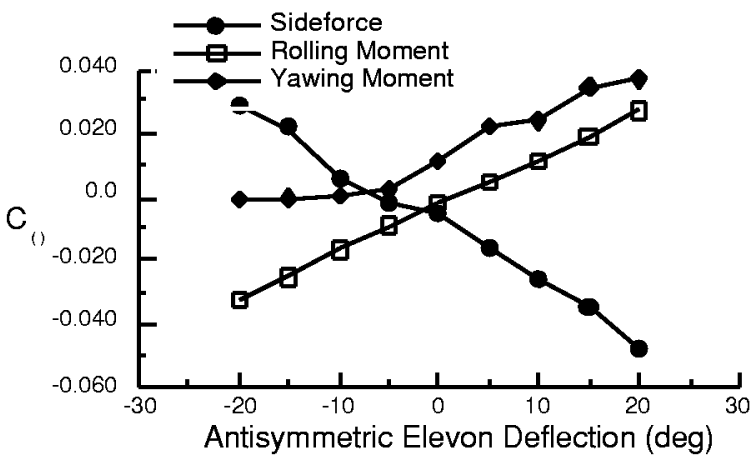

Figure 11 - side force, rolling moment, and yawing moment coefficient due to antisymmetric elevon for two-batten latex configuration, ( $q=1.6$ psf, trim power).

The trim conditions for the two-batten latex membrane configuration are presented in Table 2 . The three dynamic pressure values that are shown correspond to flight speeds of roughly 20,25 , and 28 miles per hour. These trim conditions were obtained experimentally by iterating between motor rpm, angle of attack, and symmetric elevon deflection until the lift balanced a vehicle weight of $0.16 \mathrm{lbs}$, , and total drag and pitching moment were zero.
Table 2 - Experimental and analytical longitudinal trim for the two-batten latex configuration.

\begin{tabular}{|c|c|c|c|}
\hline $\begin{array}{c}\text { Dynamic } \\
\text { Pressure } \\
\text { (psf) }\end{array}$ & $\begin{array}{c}\text { Propeller } \\
\text { RPM }\end{array}$ & $\begin{array}{c}\text { Angle of } \\
\text { Attack (deg) }\end{array}$ & $\begin{array}{c}\text { Symmetric } \\
\text { Elevon } \\
\text { (deg) }\end{array}$ \\
\hline \multicolumn{4}{|c|}{ Experimental Trim } \\
\hline \hline 1.0 & 18,900 & 10.4 & -2.5 \\
\hline 1.6 & 20,600 & 5.4 & -3.5 \\
\hline 2.0 & 21,900 & 4.0 & -6.5 \\
\hline \multicolumn{4}{|c|}{ Analytical Trim } \\
\hline \hline 1.0 & - & 11.2 & -5.6 \\
\hline 1.6 & - & 5.4 & -2.5 \\
\hline 2.0 & - & 3.5 & -1.9 \\
\hline
\end{tabular}

Linear longitudinal trim analysis using the stability and control derivatives presented above are also presented in Table 2. Only lift and pitching moment trim were considered in this analysis; drag and thrust balance was ignored. These results are in good agreement with the experimental results.

At a dynamic pressure of $1.6 \mathrm{psf}$ the linear trimmed lift curve slope is approximately 2.9 (compared to 3.8 for the $\delta_{\text {sym }}=0$ case) due to the effect of symmetric elevon deflection required to trim in pitch. Assuming sufficient thrust is available, the maximum trimmed lift coefficient that can be achieved is approximately 1.6. This trim condition corresponds to the maximum negative symmetric elevon deflection of -25 degrees, a vehicle gross weight of 0.35 pounds (about three times the vehicle empty weight), and an angle of attack of 22.4 degrees. Typical payloads are not likely to result in gross weight greater than about 0.25 pounds and so trim should not require excessive control deflections or angles of attack.

\section{Structural Deformation of Aeroelastic Wing}

It was shown previously that the flexible wing is able to operate over a wider range of angles of attack without stalling. Understanding how this is accomplished requires determining how the wing responds to changes in the flow conditions. Two methods were used to measure the structural deformation of the wing under various loading conditions - PMI and videogrammetry. Both of these methods have the virtue that they do not require direct contact with the vehicle. This is especially important for the small highly flexible wing of the UFMAV where it is difficult, if not impossible, to use typical sensors (e.g. accelerometers, strain gauges) without altering the dynamics of the wing. 


\section{PMI}

PMI uses optical methods and digital image processing to create contour maps of the surface of an object. $^{[6]}$ The maps represent mean quasi-static deformation of the surface. In addition, it is possible to determine the variance of the deformation about the quasi-static shape. The measurement accuracy depends on the resolution of the digital image and the field of view. In this case, very fine details of the wing shape could be obtained. Analysis of the PMI data is ongoing but some preliminary results are presented here.

Figure 12 shows the mean chordwise deformation of the wing at three spanwise locations, inboard, midspan and outboard, that roughly correspond to locations at which videogrammetry data were collected. The results
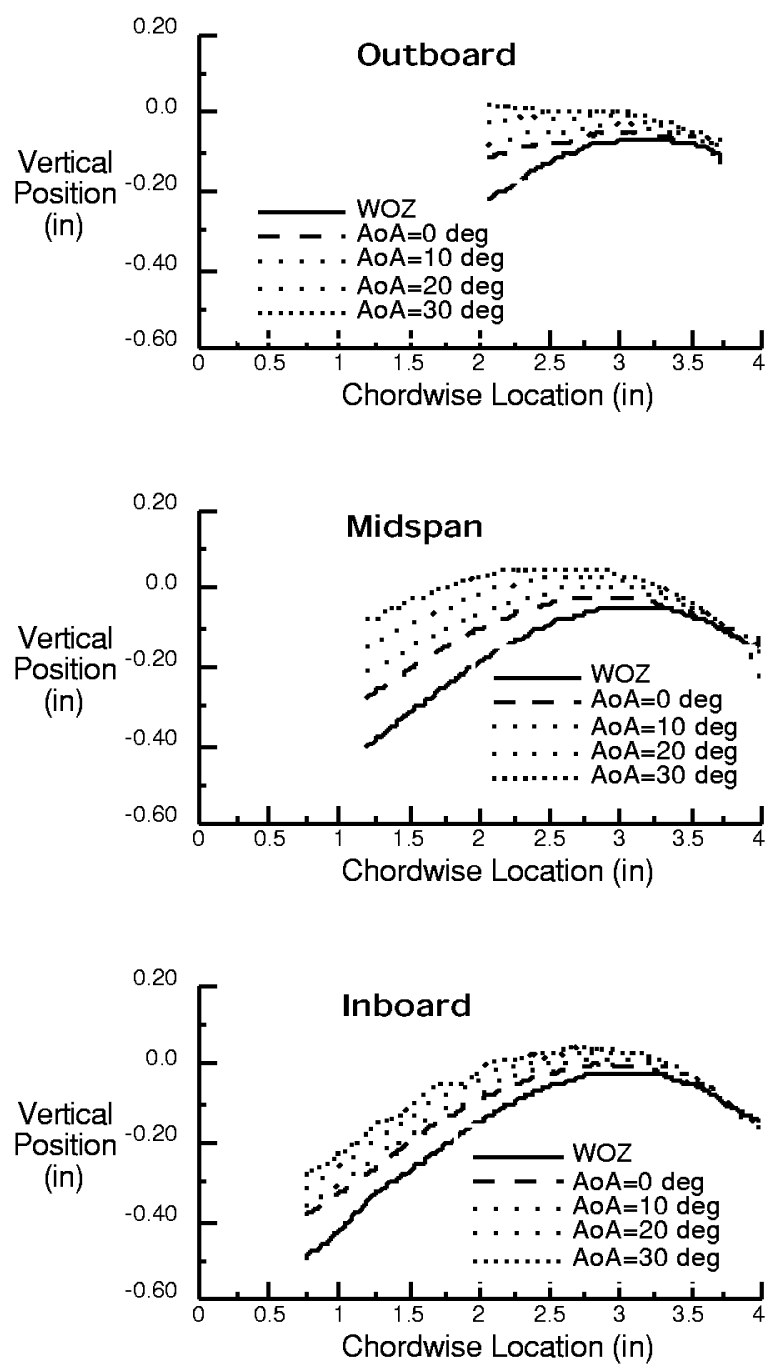

Figure 12 - wing camber of two-battened latex configuration for range of angles of attack

$$
(q=1.6 \text { psf, trim power). }
$$

shown are for the two-batten latex configuration. The wing leading edge is near a chordwise locaton of 4 inches. The chordwise deformation is presented relative to the wing at $\mathrm{q}=0 \mathrm{psf}$, i.e., wind-off zero (WOZ). The deformation data is determined at $\mathrm{q}=1.6$ psf and trim power setting at four angles of attack: 0 , 10,20 , and 30 degrees.

It is clear from these plots that the wing undergoes significant deformation. The maximum displacement of the membrane is approximately 0.25 inches at 30 degrees of vehicle incidence. The effect is to gradually reduce the camber of the wing as angle of attack increases. The degree to which the camber is reduced increases with span. Thus, though the vehicle may be at 30 degrees incidence, the wing sees a much smaller local angle of attack.

\section{Videogrammetry}

Videogrammetry also uses optical methods and digital image processing techniques to obtain structural deformation. ${ }^{[7]}$ Videogrammetry is able to capture the dynamic behavior of the surface assuming that the frame rate is sufficiently fast to capture the salient dynamics. Due to the high frequencies associated with the vibration of the batten/membrane wing very high frame rates are required to characterize the dynamic response of the UFMAV wing. A high speed videogrammetry system sampling at 850 frames per second was used in this study.

Analysis of the videogrammetry data is ongoing and only preliminary results will be discussed in this paper. An example of the results obtained from high speed videogrammetry is shown in figure 13 . The time response data at nine locations on the wing were recorded and analyzed. The mean and peak-to-peak dynamic deflections of the nine points are given. The data were also analyzed to determine the frequency content of the dynamic motion. The results indicate

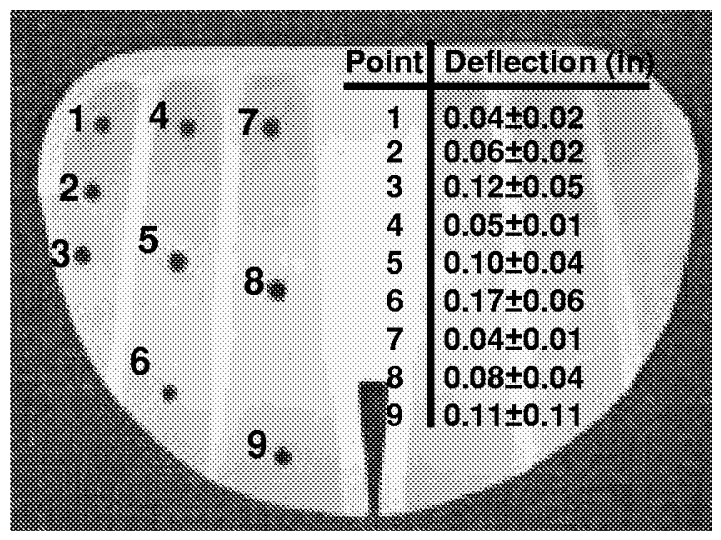

Figure 13 - videogrammetry analysis of two-batten latex config., $(q=1.0$ psf, trim power, $\alpha=8 \mathrm{deg})$. 
that there are several frequencies of vibration which primarily consist of membrane motions. The dominant frequency occurs at approximately 140 hertz and involves motion of the entire wing.

Further analysis of the PMI and videogrammetry data is intended to provide insight into the aeroelastic behavior of the wing and provide a means for validating structural dynamic and computational fluid dynamic analysis. The static and dynamic deformation data are currently being used to accurately describe the shape of the wing to generate grids for computational fluid dynamics studies.

\section{Flow Visualization}

Smoke and helium bubbles were used to perform simple flow visualization of the UFMAV for different wing configurations and flight conditions. Figure 14 shows a sample of the smoke flow video. Several qualitative aspects of the aerodynamics of the vehicle were identified.

The wing tip vortices appeared to be much weaker for the more flexible one-batten and two-batten latex membrane wings than for the more rigid wings. The latex membrane wings also exhibit a billowing of the membrane between the battens, especially at high angles of attack (see figure 14).

It was also observed that the flow over the horizontal tail and elevons was very consistent across the entire range of angle of attack. The flow did not appear to separate from the upper surface of the tail, even at angles of attack near stall. This observation is consistent with the relatively linear behavior of the control effectiveness and insensitivity to changes in angle of attack (see figures 10 and 11).

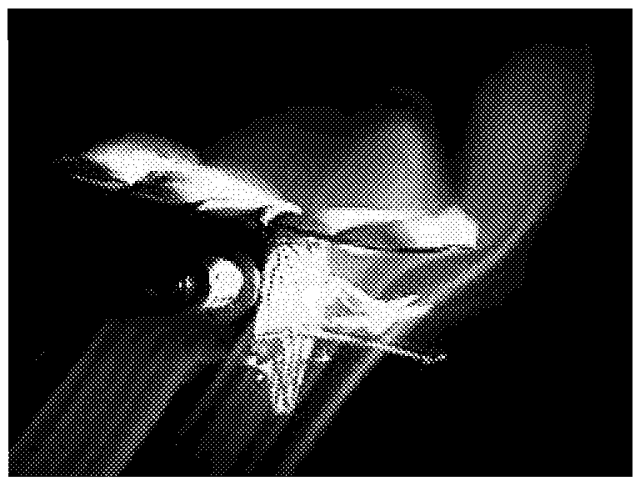

Figure 14 - smoke flow visualization of UFMAV.

\section{Concluding Remarks}

An aeroelastic fixed wing micro aerial vehicle concept has been the subject of research to determine the degree to which the innovative membrane wing enhances vehicle performance. Wind tunnel testing was performed to identify the aerodynamic properties of the vehicle, and in particular the effects of the membrane wing.

The results indicate that the elastic membrane wing allows the vehicle to achieve higher angles of attack without stalling. This fact coincides with significant static deformation of the wing under load, particularly at higher angles of attack. It appears that the deformation allows the wing to see a smaller effective angle of attack at high vehicle attitudes. The deformation also appears to contribute to weaker wing tip vortices. It is likely that there is some link between the vortex strength and structure, membrane billowing, and the stall resistance of the latex membrane wings. In addition, the static deformation is accompanied by extensive membrane vibration. The consequences of these various effects require additional study.

The extensible latex membrane wings exhibit somewhat better stall characteristics than the monofilm wing. However, the better durability of the monofilm membrane compared to the latex membrane and the otherwise similar static aerodynamic characteristics make the monofilm wing worthy of additional study.

It was observed that the lift to drag ratio of the vehicle described herein is significantly lower compared to other micro aerial vehicles. It was also shown that streamlining of the fuselage resulted in significant improvement in the lift to drag ratio. The implications of lower L/D should be investigated and future vehicles should make use of streamlining to improve vehicle performance.

The vehicle has been shown to be stable in all axes with the nondimensional static stability derivatives generally larger than for typical piloted aircraft. In addition, the vehicle trims near the maximum lift to drag ratio. Since the vehicle has been "tuned" using flight test experiments it is possible that the relatively large pitch and yaw stability and large dihedral enhance the vehicle's flying qualities. Additional investigation of the stability and control properties of the vehicle is needed to better understand the stability properties.

Additional wind tunnel tests and analytical studies of the aeroelastic fixed wing micro aerial vehicle are planned and underway. In particular, a six degree-offreedom quasi-static dynamic simulation model of the vehicle is being developed. Additional studies will emphasize efforts to develop additional understanding of the physical properties of the membrane wing concepts and use this understanding to improve the design of the vehicle and pursue other aerospace applications. 


\section{Acknowledgements}

The authors wish to acknowledge Gary Fleming for his help in collecting and analyzing the PMI data, Al Burner and Sharon Graves for their help in collecting and analyzing videogrammetry data, the staff of the Basic Aerodynamics Wind Tunnel, and especially Pam Haley and Matt Pfenninger for their assistance in analyzing the wind tunnel data.

\section{References}

[1] Mueller, T. J. editor, "Proceedings of the Conference on Fixed, Flapping and Rotary Wing Vehicles at Very Low Reynolds Numbers," Notre Dame University, Indiana, June 5-7, 2000.

[2] Anon., University of Florida Micro Aerial Vehicle Research. http://aeroweb.aero.ufl.edu/ microav/Main.htm. January 2000.

[3] Ifju, P.G., Ettinger, S., Jenkins, D.A., and Martinez, L., "Composite Materials for Micro Air Vehicles," Society for the Advancement of Materials and Process Engineering Annual Conference, Long Beach, CA, May 6-10, 2001.

[4] Sellers, W. L., III and Kjelgaard, S. O., "The Basic Aerodynamics Research Tunnel - A Facility Dedicated to Code Validation," AIAA88-1997, May, 1988.

[5] Washburn, A. E., "The Effect of Freestream Turbulence on the Vortical Flow over a Delta Wing," Master of Science Thesis, George Washington University, December, 1990.

[6] Fleming, G. A., and Burner, A. W., "Deformation Measurements of Smart Aerodynamic Surfaces", SPIE Paper No. 378325, 44th Annual SPIE International Symposium on Optical Science, Engineering, and Instrumentation - Optical Diagnostics for Fluids/Heat/Combustion and Photomechanics for Solids, Denver, CO, July 18-23, 1999.

[7] Liu, T., Graves, S.S., Ross, R. W., Eom, K.B., Hereford, J.M., "Computer Vision as a Universal Framework for Image-Based Measurements in Aerospace Engineering and Sciences." Final Report for FY2000 ISE Project, NASA Langley Research Center. September 2000.

[8] Grasmeyer, J.M. and Keennon, M.T., "Development of the Black Widow Micro Air Vehicle." AIAA Paper No. 2001-0127, Presented at the Aerospace Sciences Meeting, Reno, NV, January 2000.

[9] Torres, G.E. and Mueller, T.J., “Aerodynamic Characteristics of Low Aspect Ratio Wings at
Low Reynolds Numbers," Proceedings of Conference on Fixed, Flapping and Rotary Vehicles at Very Low Reynolds Numbers, ed. Thomas J. Mueller, University of Notre Dame, June 5-7, 2000, pp.278-305.

[10] Blakelock, J.H., Automatic Control of Aircraft and Missiles. John Wiley \& Sons, Inc., 1965.

[11] Coleman, H.W. and Steele, W.G., Experimentation and Uncertainty Analysis for Engineers, John Wiley \& Sons, Inc., New York, 1989.

\section{Appendix}

Examples of aerodynamic forces and moments obtained from the wind tunnel test of the two-batten configuration with the motor at trim power at a dynamic pressure of 1.6 psf are shown in figures A1 through A11. Each plot contains the measured data for a single run and estimated error bounds about each data point.

Figures A1, A2, and A3 show the lift, drag, and pitching moment coefficients as a function of angle of attack. Note that thrust effects have not yet been extracted. Therefore the drag coefficient includes thrust effects (thereby negative drag at lower angles). Figures A4, A5, and A6 show the sideforce, rolling moment, and yawing moment coefficients as a function of sideslip angle. Figures A7 and A8 show the lift and pitching moment coefficients as a function of symmetric elevon deflection and figures A9 - A11 show the sideforce and rolling and yawing moment coefficients as a function of antisymmetric elevon deflection.

Error bars are included in figures A1 - A11 to indicate the accuracy of the measured data. The uncertainty analysis was performed using the method in reference 11 and includes the errors associated with resolving the individual balance forces and moments, the ability to determine dynamic pressure, and the ability to determine geometric quantities (planform area, mean aerodynamic chord, span).

The majority of the uncertainty is attributable to the precision of the forces and moments measured by the 6-component strain gauge balance. The balance that was used was designed for measuring larger forces than are produced by the UFMAV. Since the measured forces and moments are small compared to the full scale of the balance, the uncertainty is large compared to the measured data. This is especially true for sideforce and rolling and yawing moments due to sideslip angle, and in all the quantities associated with changes in control deflections. 


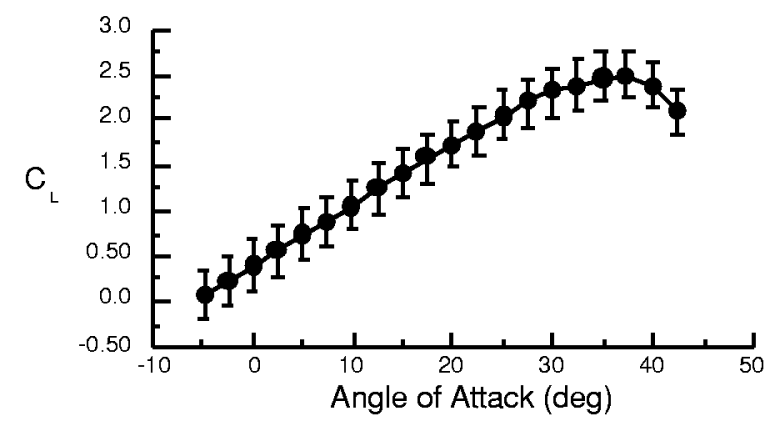

Figure A1 - lift coefficient vs. angle of attack for twobatten configuration ( $q=1.6$ psf, trim power).

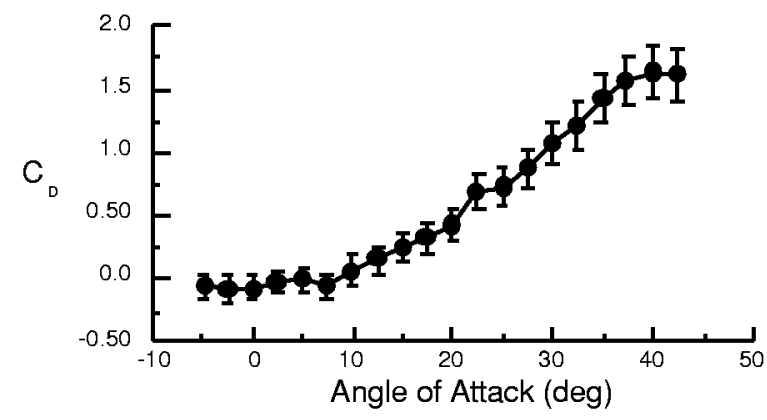

Figure A2 - drag coefficient vs. angle of attack for twobatten configuration ( $q=1.6 \mathrm{psf}$, trim power).

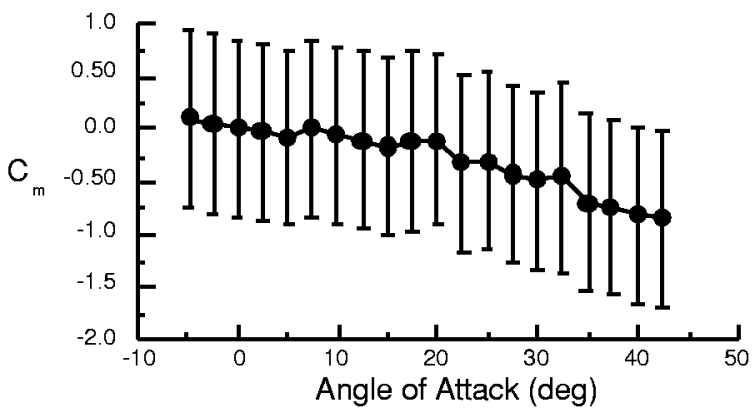

Figure A3 -pitching moment coefficient vs. angle of attack for two-batten configuration $(\mathrm{q}=1.6 \mathrm{psf}$, trim power)

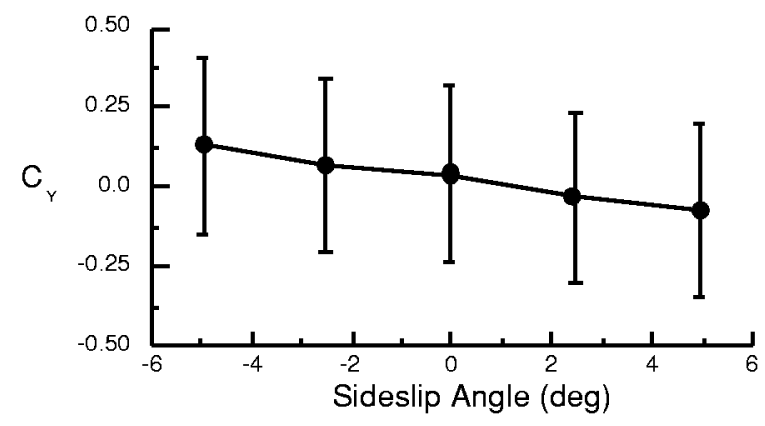

Figure A4 - sideforce coefficient vs. sideslip angle for two-batten configuration ( $\mathrm{q}=1.6 \mathrm{psf}$, trim power).

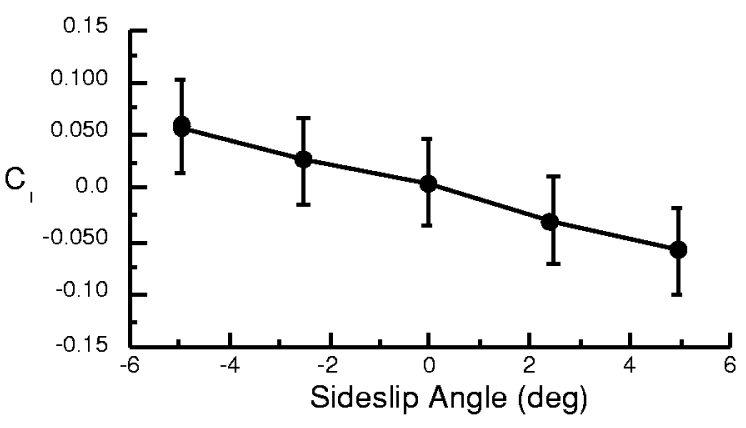

Figure A5 -rolling moment coefficient vs. sideslip angle for two-batten configuration $(q=1.6$ psf, trim power $)$.

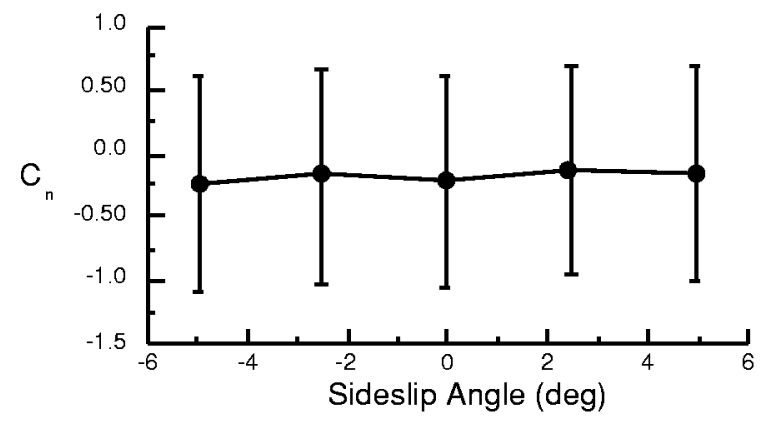

Figure A6 -yawing moment coefficient vs. sideslip for two-batten configuration ( $q=1.6 \mathrm{psf}$, trim power).

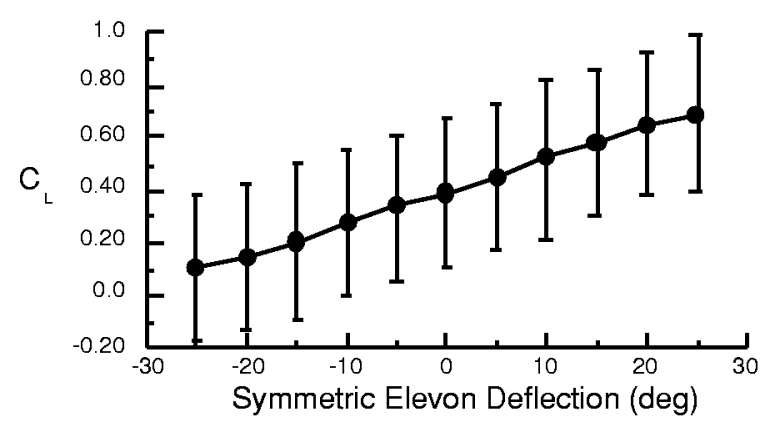

Figure A7 - lift coefficient vs. symmetric elevon for two-batten configuration ( $q=1.6 \mathrm{psf}$, trim power).

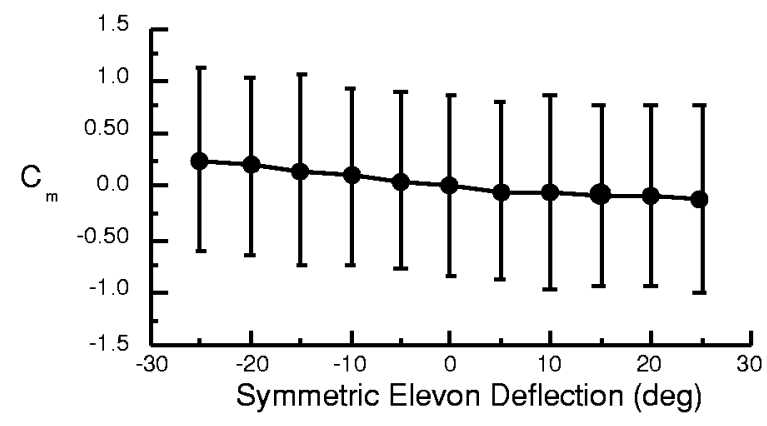

Figure A8 - pitch moment coefficient vs. symmetric elevon for two-batten config. ( $q=1.6$ psf, trim power). 


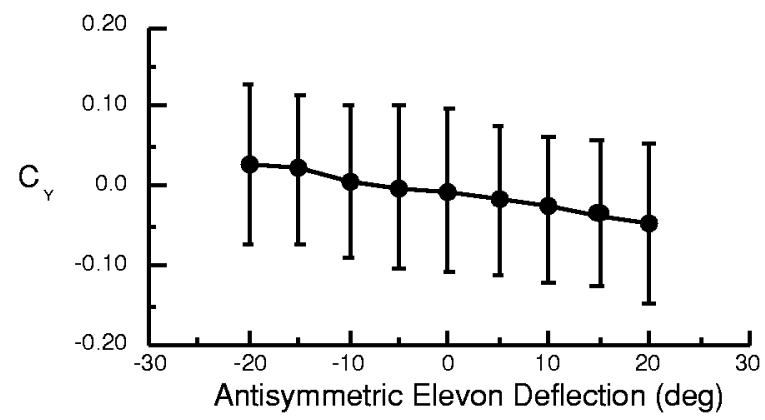

Figure A9 - sideforce coefficient vs. antisymmetric elevon deflection for two-batten configuration $(q=1.6$ psf, trim power).

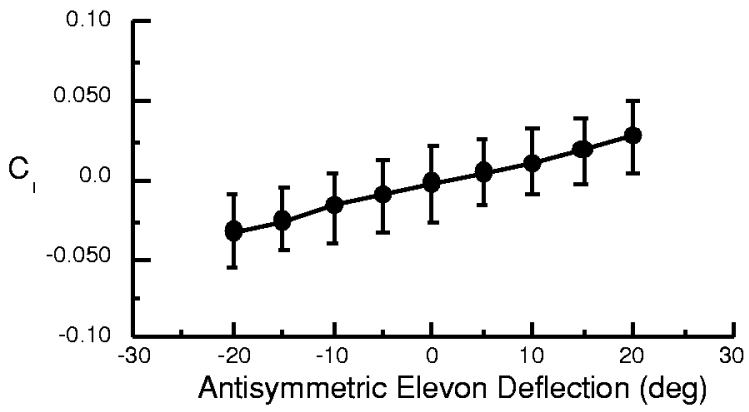

Figure A 10 - rolling moment coefficient vs. antisymmetric elevon deflection for two-batten configuration ( $q=1.6 \mathrm{psf}$, trim power).

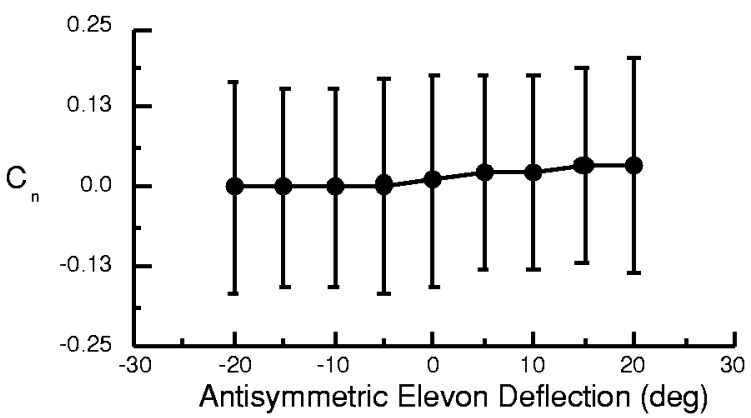

Figure A11 -yawing moment coefficient vs. antisymmetric elevon deflection for two-batten configuration ( $q=1.6 \mathrm{psf}$, trim power). 